\title{
Los concilios mexicanos promo- tores del libro y de la lectura en el siglo XVI
}

\author{
Rosa María Fernández de Zamora *
}

Artículo recibido:

24 de abril de 2007.

Artículo aceptado:

23 de abril de 2008.

\section{RESUMEN}

El artículo intenta demostrar que los Concilios Provinciales Mexicanos, a los que siempre se los ha relacionado con el control y la censura de los impresos, también impulsaron la impresión de libros y la lectura en el México del Siglo XVI.

Palabras clave: Impresos mexicanos; Concilios provinciales; Siglo XVI.

* Centro Universitario de Investigaciones Bibliotecológicas de la UNAM, México. rmfe@servidor.unam.mx 
Mexican councils: promoters of the book and reading in the XVI century

Rosa María Fernández de Zamora

The paper intends to demonstrate that Mexican provincial councils, which are always related to control and censorship of writings, also promoted book printing and reading in XVI century Mexico.

Keywords: Mexican prints; Provincial councils; XVI century.

\section{INTRODUCCIÓN}

E 1 análisis de las condiciones en que se estableció la imprenta en la Nueva España, primera imprenta de caracteres móviles fuera de Europa, es esencial para comprender ese fenómeno de tan marcada influencia en la vida colonial. El tema, vasto y complejo, ha dado origen a variados y valiosos estudios, ya que puede abordarse desde diversos enfoques. Uno de los más significativos ha sido estudiar a los hacedores de la singular producción bibliográfica del siglo XVI novohispano. En este aspecto destaca una institución, la Iglesia, y sus miembros más distinguidos, los obispos. De estos los más involucrados fueron Fray Juan de Zumárraga, Alonso de Montúfar y Pedro Moya de Contreras ${ }^{1}$ ya que en conjunción con las autoridades civiles fueron quienes otorgaron privilegios y licencias para la impresión de los libros.

Las autoridades civiles introdujeron "los privilegios”, que le daban exclusividad a un impresor por un tiempo determinado, para una obra o por todas las que se imprimían en un lugar, tal fue el caso de Juan Cromberger en la ciudad de México, privilegio que desautorizaba que otro impresor pudiera hacer lo que él. Fueron notorios los privilegios de exclusividad para imprimir cartillas, actividad que redituaba grandes ganancias. En España, y más tarde también en la Nueva España, además del privilegio, había que cumplir con otros requisitos como la licencia o autorización para imprimir una obra, que otorgaba el rey o sus representantes, y la aprobación de un experto que examinara el contenido de la obra.

1 Juan de Zumárraga, franciscano, fue el primer arzobispo de México 1528-1548, Alonso de Montúfar, dominico, fue el segundo, 1551-1572 y Pedro Moya de Contreras, seglar, fue el tercero, $1573-1586$. 


\section{LAS JUNTAS Y LOS CONCILIOS PROVINCIALES MEXICANOS}

A medida que avanzaba la evangelización de México y se iba comprobando la extensión territorial y la complejidad étnica y cultural de la Nueva España, los frailes consideraron pertinente reflexionar acerca de sus actividades en esta nueva tierra.

Antes de celebrar formalmente el primer concilio mexicano en la ciudad de México se convocaron varias juntas eclesiásticas para coordinar métodos de evangelización así como los textos necesarios y convenientes para tal labor. $^{2}$

La primera Junta eclesiástica o apostólica, como fue denominada, se llevó a efecto en 1524 bajo la conducción de fray Martín de Valencia; a ella asistieron diecinueve religiosos, cinco clérigos y cinco letrados, y contó con la asistencia de Hernán Cortés. De hecho los diecinueve religiosos pertenecían casi todos a la orden franciscana, única entonces establecida en la Nueva España. Se discutieron allí temas relacionados con la educación cristiana y con la administración de los sacramentos.

La segunda Junta se celebró en 1532 bajo la conducción de Sebastián Ramírez de Fuenleal, obispo de Santo Domingo y presidente de la segunda audiencia mexicana, carácter con el cual fungió como representante del rey. A esta Junta ya asistieron algunos miembros de la orden de predicadores, los dominicos. La Junta se abocó a la tarea de organizar a las poblaciones indígenas, que estaban muy dispersas, y por lo mismo eran difíciles de evangelizar y de controlar políticamente. Se decidió fundar numerosos conventos con la intención de agrupar a la población indígena en torno a ellos. Quizá en esos momentos comenzó la distribución territorial que adoptaron las órdenes mendicantes. ${ }^{3}$ Fray Juan de Zumárraga, quien como primer obispo debió encabezar la reunión, se encontraba entonces en España y de ahí la presencia de Fuenleal. Contando ya con la presencia del primer obispo se efectuaron otras tres juntas, en 1537, 1539 y 1546.

En 1537 llegaron a la Nueva España noticias sobre la futura realización de un concilio general, que posteriormente se reuniría en Trento, pero el rey

2 Sobre las juntas y concilios existen numerosos escritos publicados, para este estudio se consultaron entre otros: Constituciones del arçobispado y provincia dela muy insigne y muy leal ciudad de Tenuxtitla México dela nueva España, México, Juan Pablos, 1556; Concilios provinciales primero y segundo, celebrados en la muy noble, muy leal ciudad de México... Dálos a luz Francisco Antonio Lorenzana, México, Imprenta Superior de Gobierno, Joseph Antonio de Hogal, 1769; Robert Ricard, La conquista espiritual de México, 2 ed. México, FCE, 2002, Concilios provinciales mexicanos, Época colonial, Edición digital, México, UNAM, Instituto de Investigaciones Históricas, 2004, Disco compacto (Serie instrumentos de consulta, 4).

3 R. Ricard, op. cit. pp. 139-163. 
dispuso que los obispos mexicanos no asistieran asegurándoles "[...]que él tomaba a su cargo obtener para ello el beneplácito del Papa". ${ }^{4}$

En la Junta de 1539, convocada para cumplir con el mandato real comunicado por el virrey Antonio de Mendoza, se reunieron los obispos, entre ellos don Vasco de Quiroga, primer obispo de Michoacán y los provinciales de las órdenes mendicantes, y convinieron varias disposiciones relacionadas con el gobierno de la Iglesia así como el bautismo de los adultos y la necesidad de elaborar manuales para tal fin.

La junta, menciona García Icazbalceta, eligió al señor Quiroga para que redactara el Manual de adultos, que efectivamente fue impreso a fines de 1540, Icazbalceta añade que:

Aunque en 1560 se publicó nuevo Manual de Sacramentos, ordenado por el primer Concilio, los franciscanos le adoptaron solamente para los hijos de los españoles, y en el último tercio del siglo usaban todavía para los indios el venerable Manual de $15400^{5}$

La Junta de 1546 fue también muy importante por los temas tratados y en ella participaron, entre otros, fray Juan de Zumárraga, don Vasco de Quiroga, fray Bartolomé de las Casas y el visitador real. Los problemas que se debatieron versaron sobre la encomienda, el pago del diezmo, los derechos de los indígenas, la petición de la creación del tribunal de la Inquisición en la Nueva España y, lo más importante, "[...] se dispuso que se compusieran dos doctrinas destinadas a los indios, una breve y otra extensa, cuyo acuerdo cumplió fielmente el señor Zumárraga". ${ }^{6}$

Entre tanto, en paralelo con la Junta de 1546, había empezado ya a sesionar un poco antes y tras muchas dilaciones, el Concilio reunido en Trento, que se había postergado por la tensión entre Roma y el emperador Carlos V. Las querellas cedieron ante la urgente necesidad de contener el avance de la reforma protestante que se iba extendiendo en múltiples frentes: en Alemania encabezada por Martín Lutero, en Francia y Suiza dirigida por Calvino y en Inglaterra Enrique VIII había roto también con Roma. El Concilio sesionó en varias etapas durante un periodo de casi veinte años y sus resoluciones tuvieron una gran influencia en el mundo católico y por tanto en la Nueva España.

4 Joaquín García Icazbalceta, Fray Juan de Zumárraga.Primer obispo y arzobispo de México, Buenos Aires: Espasa Calpe, 1952, p. 105. (Colección Austral). Dice además García Icazbalceta que "El señor Zumárraga envió al Concilio, con fray Juan de Oseguera, agustino, unos Apuntamientos acerca de las cosas de la Nueva España." 
Tras estas juntas, la Iglesia novohispana fue de nuevo convocada bajo la denominación más formal de "concilios". En derecho canónico se da este nombre a la junta de personas eclesiásticas, especialmente obispos, que tiene por objeto deliberar sobre asuntos eclesiásticos. Los puede haber generales o provinciales, la convocatoria de estos últimos corresponde al arzobispo primado, en el caso específicamente novohispano, los concilios:

[...]representan la institucionalización de las disposiciones eclesiásticas más acabadas, importantes y generales que sirvieron como punto de referencia obligado en las reglas de representación social en la Nueva España[...] Los concilios provinciales representaron en primer lugar la renovación institucional de la fe[...] pero también intentan regular ciertos hábitos, corregir lo que consideraban excesos y aclarar puntos que habían originado controversias o generado diversas interpretaciones[...] hay[...] reafirmaciones de la autoridad diocesana, punto que Trento había marcado como fundamental para la organización eclesiástica y que retomarán permanentemente los concilios provinciales. ${ }^{7}$

\section{Primer CONCILIO PROVINCIAL MEXICANO}

Fue celebrado en la muy noble y leal ciudad de México en 1555, del 29 de junio al 7 de noviembre, convocado por el segundo arzobispo de México Alonso de Montúfar, quien congregó a los obispos para regular la organización de la Iglesia,

[...]fue, sin lugar a dudas, uno de los acontecimientos centrales en la vida eclesiástica y política de la Nueva España del siglo XVI. Conviene insistir en que su objetivo no fue el de llevar a la práctica el de Trento, entonces en pleno proceso[... $]^{8}$

Es más, se puede decir que el primer Concilio se adelantó al de Trento en el control de los impresos. Este primer Concilio tiene especial interés para el estudio de los impresos mexicanos porque, además de la importancia de los temas debatidos, fue el único cuyos resultados se imprimieron durante el siglo XVI.

Los decretos fueron promulgados los días 6 y 7 de noviembre de 1555 en la catedral de México, con la presencia de los prelados, audiencia y representantes de los

7 Francisco Javier Cervantes Bello, "Presentación”, en Concilios Mexicanos Provinciales. Época colonial, op. cit, p. 3 .

8 Leticia Pérez Puente, Enrique González González, Rodolfo Aguirre Salvador. "Estudio introductorio", en Los concilios provinciales mexicanos primero y segundo, en Concilios provinciales mexicanos. Época colonial... op. cit. p. 9. 
cabildos catedralicios, aunque con ausencia del clero regular, Montúfar se apresuró a imprimirlos. ${ }^{9}$

Los decretos publicados como Constituciones del arçobispado y provincia de la muy insigne y muy leal ciudad de Tenuxtitlan Mexico de la nueua España, salieron de las prensas de Juan Pablos, el 10 de febrero de 1556. El contenido de estos decretos propició el comienzo de una lucha de las órdenes mendicantes contra el clero secular por conservar los privilegios que hasta entonces habían tenido.

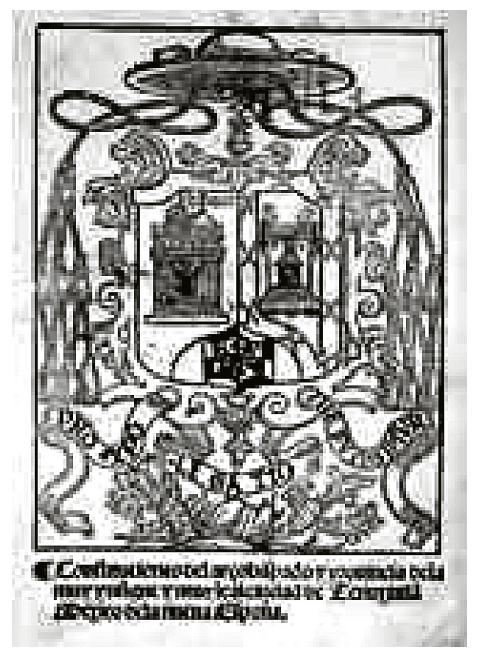

Los 93 capítulos que forman la obra ofrecen un interesante cuadro sobre las costumbres de la población en general y de los clérigos en particular, muchas de las cuales eran consideradas nocivas para la vida cristiana. Se señalan ahí las normas que debían seguirse para combatir tales costumbres con la práctica religiosa, especialmente con la administración de los sacramentos y la enseñanza de la doctrina cristiana.

El cuadro de costumbres se deduce de las prohibiciones que mencionan; si hubo que recurrir a ellas fue, sin duda, porque eran prácticas comunes y cotidianas, una muestra:

Que ninguno vaya a los sortilegos, o Encantadores, o Adevinos[,..] Que los medicos, y cirujanos amonesten a los enfermos, que se confiesen[...] que el medico despues que supiere, que el enfermo no se ha confesado no lo vaya a visitar la segunda 
vez[...] Que en las iglesias no se hagan sepulcros altos, ni haya tumbas[...] Que no se hagan representaciones en las iglesias[...]porque se siguen muchos inconvenientes, y muchas veces traen escándalos en los corazones de algunas personas[...] Que en las iglesias no se hagan Consejos, ni Ayuntamientos, ni en Cimenterios juegue nadie[...] Que no se hagan matrimonios clandestinos[...] Contra los que se casan dos veces[...] Que no tengan los casados, ni los que no lo fueren, mancebas, especialmente parientas[...] Que no traigan armas los clerigos[...] Que los clerigos no jueguen a tablas, dados, naipes... Que los clerigos no tengan en su compañia muger que el derecho reputa por sospechosa, ni concubina[...] Que se modere la música, e instrumentos, y que no haya escuelas donde no obiere religiosos, o clérigos, que tengan cuidado de ellas... Que los tianguis no se hagan en domingo, ni en otras fiestas solemnes[...] ]etcétera.

Por otra parte, los capítulos relacionados con los libros y la imprenta en México no son numerosos, pero tendrán una importante influencia en los impresos mexicanos y en la práctica de la lectura; tales capítulos son los siguientes:

\section{Capitulo tercero}

De la Doctrina delos niños. Porque las buenas costumbres, tanto mejor se saben y guardan quanto mas enla niñez se aprenden: ordenamos y mandamos: Sancto concilio approbante, que en todas las yglesias de nuestro arcobispado y provincia, se deputen y señalen personas suficientes, y de buen exemplo y vida, que eseñen a los niños, principalmente la doctrina christiana[...]Item [...] que los maestros, que enseñan a los niños, en sus escuelas hagan leer, y dezir la dicha doctrina cada dia una vez, y no les enseñen a leer ni escrevir, sin que juntamente se les enseñen las dichas oraciones y las otras cosas contenidas en la dicha tabla: lo qual les mandamos que hagan y cumplan, so pena de dos pesos, aplicados al hospital y obras pias. $^{10}$

En este mandato podemos ver cómo desde entonces se puso atención en la enseñanza a los niños por considerar su facilidad para el aprendizaje, modalidad que aún persiste aunque sin mucho éxito, por no considerar el entorno familiar que los rodea.

10 Constituciones op. cit. fo iiiia. Las citas de este primer Concilio están basadas en la primera impresión de 1556. En la medida de lo posible se sigue la ortografía original, Se proporcionan también los datos de la edición de Lorenzana de 1769 por ser la más conocida: Concilio primero, en Lorenzana p. 44. En adelante las citas se harán: Constituciones fo... y Lorenzana p. Se encuentran también en el disco compacto. 


\section{Capítulo quarto}

Que se hagan Doctrinas para los indios[...] ordenamos y mandamos la una breve y sin glosa[...] y la otra con declaración sustancial delos artículos de la fe, y mandamientos y pecados mortales[...] y se traduzgan a muchas lenguas, y se impri$\operatorname{man}[\ldots]^{11}$

Antes del primer Concilio se habían impreso diez doctrinas, cinco en castellano y cinco en lenguas castellana y mexicana, que incluían la Breve y más compendiosa doctrina de 1539 de la cual no se conservan ejemplares. Después se imprimieron además de en castellano y mexicano en otras lenguas como michuacano, zapoteco, misteco, guasteco, otomí, chuchona; no se sabe con certeza de cuantas obras se trata porque a lo largo de la historia se mencionan títulos de doctrinas y catecismos que se dan por impresos, pero de los cuales no se ha conocido ningún ejemplar.

\section{Capitulo quarenta y cinco}

Dela instrucion que an de guardar los examinadores, con los que han de ser ordenados para primera corona. Se ocupa de los conocimientos que deben tener los que se han de ordenar, entre ellos:

Para grados. Mandamos que los que ovieren ordenar de grados[...]que sepan alomenos construir una oracion, y dar cuenta de las reglas del arte. Y assi mesmo sepan algo de canto llano, alomenos solfear[...] Los que ovieren de ordenar de epistola, Item, que sean buenos gramáticos, y sepan hablar latin, y construyr qualquiera latinidad, y dar cuenta de ella, por los preceptos de gramatica, de mas desto, sean cantores, de canto llano. Para los que andeser curas[...] que sean examinados, con todo rigor en la administracion delos sacramentos, en especial de la penitencia, y confessión, y casos de conciecia. Item que si por necesidad urgente, se ofreciere: que alguno sea admitido a ser cura, que no sepa todo lo susodicho, que en tal caso los nuestros examinadores le manden tener libros, por donde estudie enlo que estuviere falto, o defectuoso[...] Item[...] para declarar el evangelio[...] tenga libros necesarios, y para los casos de conciencia, como son la biblia, sant vicente, o otro buen sermonario[...] $]^{12}$

Los requerimientos señalados en este capítulo explican la necesidad de imprimir libros de música, que pese a su dificultad técnica se imprimieron en 
México de 1556 a 1589. Se expone, igualmente, la necesidad de gramáticas latinas y otros libros que en su mayoría fueron traídos de Europa, y cuya presencia se comprueba en las colecciones novohispanas que se conservan en las bibliotecas, pero que también repercutieron en las imprentas mexicanas, las que publicaron confesionarios, sermonarios, una gramática latina y libros de liturgia.

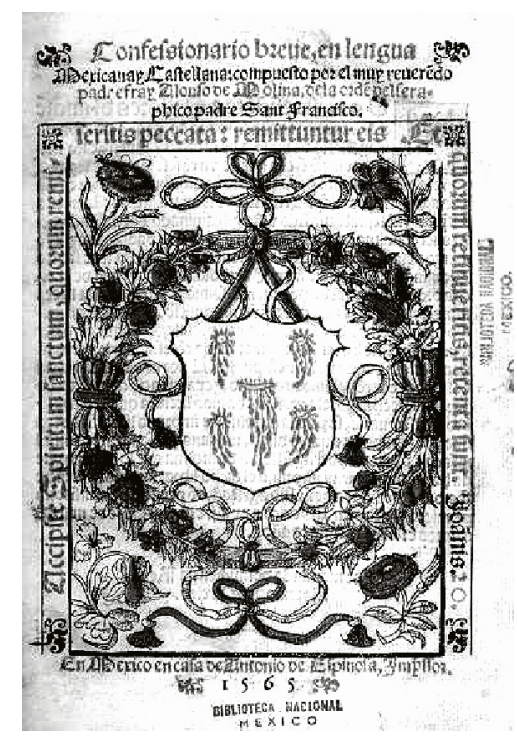

Confesionario breve, 1565

\section{Capitulo sesenta}

Que los clerigos que ovieren de confesar españoles o indios, sean primero examinados[...]que los clérigos que se proveyere para administrar los sacramentos, y doctrinar alos indios, seles mande aprender la lengua de los indios, dentro de cierto tiempo[... $]^{13}$

Antes del Concilio se había impreso sólo un vocabulario en lengua de los indios, el de Alonso de Molina en castellano-mexicano. Este mandato promueve la elaboración e impresión de artes y vocabularios en las lenguas indígenas más usadas por los religiosos, pero sólo siete gramáticas y seis vocabularios impresos en el siglo XVI han llegado hasta nuestros días. Se sabe que se escribieron muchos más textos de este tipo, pero no fueron impresos o bien se perdieron. 


\section{Capitulo sesenta y siete}

Que todos los sacerdotes baptizen, y casen, y administren los otros Sacramentos por el Manual, que de nuevo se imprimira. ${ }^{14}$

Este mandato se cumple con la publicación del Manuale Sacramentarum secundum usum ecclesiae mexicanae. Noviter impressum, cum quibusdam additionibus utilissimis: quae omnia in sequente pagella reperie, impreso por Juan Pablos en 1560, por orden de Montúfar, “[...]para que se use este Manual y no otro, bajo pena a su arbitrio". No se conoce una impresión mexicana del Manual anterior a éste.

\section{Capitulo sesenta y nueve}

Que no se den a los yndios sermones en su lengua, y que ninguna doctrina se traduzga en lengua de yndios, sino fuere examinada por clerigo o religioso que entienda la lengua en que se traduze. Muy grandes inconvenientes hallamos, que se siguen de dar sermones enla lengua alos indios, asi por no los entender, como por los herrores y faltas, que hazen quando lo trasladan. Porende statuimos y mandamos, que de aquí adelante, no se den sermones a los indios para trasladar, ni tener en su poder: y los que tienen seles tomen, y recojan[...] Assimesmo, ninguna doctrina, se traduzga en lengua de indios, sin que primero passe, por la censura, y examen de personas religiosas, y eclesiásticas: que entiendan la lengua en que se traduze. ${ }^{15}$

Esta disposición y la del capítulo sesenta repercuten en la publicación de gramáticas y vocabularios en diferentes lenguas indígenas, así como en las aprobaciones religiosas, a cargo de conocedores de la lengua que se traduce, las cuales aparecen en las hojas preliminares cuando son impresas, lo que no sucedía en las publicaciones precedentes.

\section{Capitulo setenta y cuatro}

Es el único mencionado en los estudios bibliográficos por ser el que directamente incide en los impresos, y señala lo siguiente:

Que ninguno imprima libros, ni obras de nuevo sin licencia, ni las assi impressas venda, y que ningun mercader ni librero venda libros, sin que primero muestre las 
memorias de ellos, y sean examinados por el diocesano, o por quien el lo cometie$\mathrm{re}^{16}$

Hay que tener presente que antes de esta disposición, el contrato de Cromberger y Juan Pablos obligaba a cumplir la pragmática de 1502, como se hacía en Sevilla, donde se mandaba tener la licencia autorizada; estas licencias aparecían en los colofones y generalmente sólo las otorgaba el obispo.

Así, este primer Concilio tendrá repercusión en el mundo del libro impreso en México, y en el traído de España, no sólo en cuanto a los diversos contenidos señalados sino también en la estructura física de los libros mexicanos, lo que cambiará al incluir en las hojas preliminares las licencias obligatorias o licencias legales que hasta entonces no se imprimían al comienzo del libro, sino que se mencionaban algunas veces en los colofones. El primer libro que cumplió con este mandato que debía llevar las licencias del virrey Luys de Velasco en las hojas preliminares y la del obispo Alonso de Montúfar, aunque ésta en el colofón, es el Sumario compendioso de las quentas de plata y oro, impreso por Juan Pablos Bressano el 29 de mayo de 1556; lo que cumplía con las dos licencias que mandaba este primer concilio tres meses después de que sus Constituciones o resoluciones habían sido impresas, en febrero de ese mismo año. Más aún, antes de que empezara el Concilio se imprimió la obra de fray Alonso de Molina Aqui comiença vn vocabulario en lengua Castellana y Mexicana, Juan Pablos, 4 de mayo de 1555, en la que por vez primera aparecen en el colofón las licencias del virrey y del arzobispo, así como la aprobación del revisor, información muy diferente de la que aparece en los colofones de otras obras que le antecedieron como son : la Doctrina cristiana en lengua Mexicana, 1553, la Recognitio Summularum, 1554 y la Dialectica resolutio, 1554.

Finoclaobia.

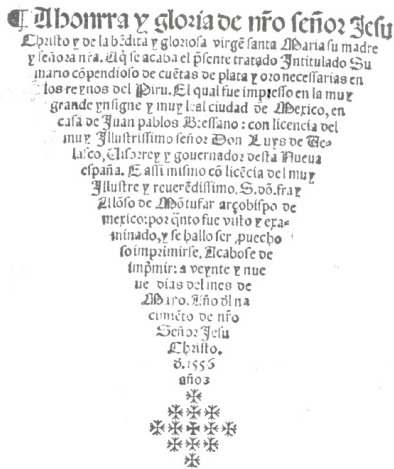

16 Constituciones fo xxvr, Lorenzana p. 149. 
Así pues, las licencias obligatorias aparecen en los libros mexicanos desde 1556, como respuesta a las resoluciones del primer Concilio mexicano, y se adelantaron a la pragmática de 1558 emitida por Felipe II. Esta importante cédula real disponía:

[...]mandamos que ningún libro ni obra de cualquier facultad que sea en latín ni en romance ni otra lengua se pueda imprimir ni imprima en estos Reynos sin que primero el tal libro o obra sean presentados en nuestro Consejo y sean vistos y examinados por la persona o personas a quien los de nuestro Consejo cometieren, y hecho esto se le de licencia firmada[...] Y porque hauiéndose de hazer y guardar lo suso dicho en todos los libros y obras[...] que en estos Reynos se ouiesen de imprimir[...]permitimos que los libros, misales, breuiarios, diurnales, libros de canto para las yglesias y monasterios, horas en latín y romance, cartillas para enseñar a los niños, flos sanctorum, constitutciones sinodales, artes de gramática, vocabularios, y otros libros de latinidad de los que se han impreso en estos Reynos, no siendo los dichos libros de que se ha dicho obras nueuas, sino de las que otra vez están impressas, se puedan imprimir sin que se presenten en nuestro Consejo ni preceda la dicha nuestra licencia, y que se pueda hazer la tal impresión con licencia de los Prelados y Ordinarios en sus distritos y diócesis, los quales examinen y vean o hagan ver y examinar a personas doctas y de letras y conciencia las tales obras y libros y las licencias que hecho esto se dieren por los Prelados y Ordinarios se pongan en principio de cada libro según que está dicho[...]pero si los dichos libros y obras fueren nuevos[...] se presenten en nuestro Consejo. ${ }^{17}$

No cabe duda de que estas disposiciones reforzaron los mandatos del Concilio Mexicano.

\section{SEgUNDO CONCILIO PROVINCIAL MEXICANO}

Éste fue convocado en enero de 1565, también por Alonso de Montúfar, para dar a conocer la cédula de Felipe II del 12 de julio de 1564, en la que ordenaba acatar los decretos del Concilio de Trento en todos sus reinos. Así, el primer capítulo se titula

17 F. de los Reyes, El libro en España y América. Legislación y censura, Madrid, Arco/ Libros, 2000, v.2, pp. 801-803. Este autor, en el v. 1 p. 207, al referirse a esta pragmática hace unos señalamientos equivocados al afirmar que "[...]las primeras obras que reflejaron en sus preliminares dichas licencias y censuras fueron las editadas por Pablos en 1558, cuyo autor fue Fr. Maturino Gilberti" "[...] y que a partir de que "[...]primero se siguió en Nueva España, este procedimiento se extendió por el resto de territorios americanos (Sic). Debe tenerse en cuenta que en esa fecha no había más imprentas en América. 
Que los Prelados guarden, y manden guardar lo ordenado, y mandado por el Santo Concilio Tridentino; sin embargo a lo largo del texto las alusiones a su contenido son muy pocas. ${ }^{18}$

Las sesiones del segundo Concilio que reunió a obispos, provinciales de las órdenes de mendicantes, oidores, regidores y visitador, duraron poco tiempo, del 15 de agosto a fines de octubre (1565). Fue también más breve en su contenido, pues contaba de sólo 28 capítulos en los que se confirman las disposiciones del primer Concilio con algunas excepciones. Vuelve a mencionarse aquí que los curas tengan "Biblias y algunas Sumas de casos de conciencia"; y que los curas tengan cuidado de aprender las lenguas de sus partidos

[...]que no se permita a los Indios tener Sermonarios, Nóminas, ni otra cosa de Escriptura escripta de mano, salvo la Doctrina Cristiana aprobada por los prelados, y traducida por los religiosos Lenguas, conforme á las Synodales de el dicho arzobispado, y Provincia. ${ }^{19}$

Además, uno de los últimos documentos titulado "Avisos para que los naturales de estos Reynos sean felices en lo espiritual, y temporal”, se dice algo muy importante en el punto IX:

Que tengan Escuela de Castellano, y aprendan los niños a leer, y escribir, pues de este modo adelantarán, sabrán cuidar su casa, podrán ser Oficiales de República, y explicarse con sus Superiores, ennobleciendo su Nación, y desterrando la ignorancia, que tienen, no solo de los Misterios de la Fé, sino tambien del modo de cultivar sus tierras, cria de ganados, y comercio de frutos, a lo que se añade ser falta de respeto hablar en su Idioma con los Superiores, o delante de ellos, pudiendo hacerlo en Castellano, aunque sea hablando poco. ${ }^{20}$

Este mandato respondía a la cédula real de 1550 que mandaba enseñar castellano a los indígenas para mejor actuar en su vida diaria, finalidad que a la fecha no se ha logrado.

Los resultados del segundo Concilio no fueron publicados durante el siglo XVI debido a los ordenamientos de la pragmática de 1558 y de la cédula del 31 de agosto de 1560, que expresamente les ordenaban a los arzobispos y obispos de Indias que no imprimieran los sínodos sin enviarlos al Consejo

18 L. Pérez Puente, op. cit. p. 23.

19 F. A. Lorenzana. Concilios op. cit. pp. 198-199, 201.

20 Ibid. p.394. 
de Indias, ${ }^{21}$ lo cual retrasó su publicación. Sus resoluciones fueron impresas por vez primera en 1769 por el arzobispo de México, Francisco Antonio de Lorenzana.

\section{TERCER CONCILIO PROVINCIAL MEXICANO}

Fue presidido por Pedro Moya de Contreras, por la gracia de Dios y de la santa silla apostólica, arzobispo de México, y también virrey de la Nueva España, y presidente de la Real Audiencia, y se celebró en 1585; sus resoluciones se manifiestan en cinco libros divididos en títulos que contienen 576 decretos de carácter normativo y un gran apego a las reformas y espíritu tridentinos. Ante la fuerte oposición del virrey Villamanrique, de la Real Audiencia, de los representantes de los franciscanos, dominicos y agustinos y otros miembros del clero de México y España que se sentían agraviados por el rigor y las penas dispuestas, más la protesta de médicos, plateros y beatas, las resoluciones no fueron publicadas hasta 1622 y duraron vigentes en la arquidiócesis de México hasta 1896 cuando se celebró el v Concilio mexicano. ${ }^{22}$

El tercer Concilio dejó un instrumento paralelo esencial para la formación del clero relacionado con el sacramento de la confesión: el directorio o directorio de confesores, que tuvo pocas repercusiones en las actividades de la imprenta mexicana puesto que después del concilio únicamente fueron publicados tres textos relacionados con la confesión; suelen también mencionarse otros textos que nadie ha visto como el Confesionario o instrucción de conciencias, para toda suerte de personas, a petición de la Congregación de Nuestra señora de la Anunciación. ${ }^{23}$

En este Concilio, como en los anteriores, se insiste en la enseñanza de la doctrina a los indios en su propia lengua, y en la necesidad de establecer escuelas donde los niños aprendan a leer y escribir; pero ya no condiciona la enseñanza al aprendizaje de las oraciones.

De importancia para la impresión de libros es la disposición que aparece en el Título I

De la Impresión y lección de libros. Ningún libro se imprima sino con la licencia del obispo. No menos por escrito que de palabra suele ser de gran daño la perversa doctrina. Por lo cual, con arreglo al decreto del concilio tridentino, establece y

21 F. de los Reyes, op. cit. vol. 2, p. 805.

22 "Aprobación del Concilio. Tercer Concilio", en Concilios provinciales mexicanos [...] p. 5 [Disco compacto] 
manda este sínodo que ninguno se atreva a imprimir, mandar imprimir, circular, ni comprar, ni vender, no tener consigo cualesquiera libros, si no es que antes hayan sido examinados y aprobados por el ordinario, y escritos e impresos con su licencia, bajo la pena de excomunión en que se incurrirá por el mismo hecho, y de cincuenta pesos que se han de distribuir por partes iguales a las obras pías, al acusador y a los gastos hechos por esta causa. ${ }^{24}$

Este mandato repite y reitera con mayor amplitud lo establecido en el capítulo setenta y cuatro del primer Concilio arriba comentado; sin embargo este título sólo menciona la licencia del obispo y no hace referencia a que había que cumplir con la pragmática vigente de 1558, de Felipe II, que señalaba la obligación de tener tanto la licencia de la Iglesia como la de la Corona, las cuales aparecen en la mayoría de los libros impresos en México.

También hay apartados relacionados con la imprenta y con el primer Concilio, por ejemplo, que ningún escrito perteneciente a la religión se publique en el idioma de los indios sin ser primero examinado por el ordinario bajo pena de excomunión y que nadie retenga en su poder libros obscenos.

En el Título II De las constituciones se aborda la autoridad de los decretos y su publicación, se derogan los decretos de los sínodos precedentes y se manda que se guarden los de este sínodo, y que se publiquen y divulguen suficientemente, además de que las catedrales tengan un ejemplar de este concilio para lo cual:

[...]haga escribir en pergaminos estos decretos y sellarlos con el sello de este sínodo y se guarden en el archivo de la iglesia metropolitana[...] Empero, después de su impresión, cuando cómodamente pueda tenerse abundancia de ejemplares, el mayordomo de cada una de las iglesias catedrales de esta provincia compre dos ejemplares, de los cuales se ponga uno en un coro y otro en otro, atados en cadenillas[...] las iglesias parroquiales[...] compren un ejemplar de dicho libro, el cual coloquen también con cadenilla en el coro o en la sacristía, donde más cómodamente se pueda tener para leerse[...] los vicarios que tienen cura de almas[...] tengan consigo un libro dentro del término de seis meses[...] si dentro del término prescrito no obedecieron a estos mandatos, sean multados en veinte pesos, de los cuales dos partes se apliquen a la iglesia[... y y la tercera al acusador. ${ }^{25}$

Sin embargo, como se mencionó, los mandatos de este Concilio sólo fueron publicados hasta 1622 . 
Las disposiciones de los concilios que se han señalado son las que tuvieron efectos importantes sobre la labor de autores, impresores y libreros y, por tanto, en los lectores. Se puede observar que después de un periodo inicial relativamente libre de restricciones, poco a poco van apareciendo limitaciones cada vez más severas, lo que sin duda influyó en la cantidad y calidad de las obras publicadas en las últimas décadas del siglo XVI.

Las resoluciones de los concilios constituyen una fuente de primer orden para el estudio de la Iglesia y de la vida colonial porque fueron obligatorias para todo el territorio de la Nueva España, y representaron el esfuerzo de la jerarquía para adaptar la disciplina eclesiástica a las necesidades y manera de ser de las nuevas cristiandades.

De los impresos mexicanos emanados de los concilios se deben destacar las Constituciones del arçobispado, 1556, por ser las únicas resoluciones de un concilio provincial de los tres celebrados en México que fueron publicadas en el siglo XVI. Esta primera edición es de difícil consulta por conservarse únicamente seis ejemplares y de ésos, sólo uno en México en la Biblioteca Cervantina en Monterrey. Estas resoluciones fueron conocidas por la edición que hizo el obispo Lorenzana en el siglo XVIII.

\section{LA LECTURA}

Existen estudios especializados que han aportado valiosa información sobre la práctica de la lectura en Nueva España, por lo que sólo se hará una somera reflexión sobre los nuevos lectores que propiciaron los concilios mexicanos y en general los impresos mexicanos del siglo XVI. ${ }^{26}$

La lectura no podía ser lo mismo para un europeo que para un indígena. El libro en su forma occidental era un objeto ajeno para las culturas mesoamericanas y fue utilizado por los españoles como herramienta de conversión y de dominio, en un inmenso esfuerzo por occidentalizar a los nuevos súbditos de Castilla.

La enseñanza de la lectura y la escritura en castellano -e incluso en latín- no fue tarea fácil, pero ya Pedro de Gante y otros religiosos, especialmente los franciscanos, observaron que en la cultura mexica los jóvenes nobles asistían a una institución educativa que los formaba para cumplir con

26 Véase entre otros: Josefina Zoraida Vázquez Vera, La historia de la lectura en México, México: El Colegio de México, 1988, (Historia de la educación en México); Pilar Gonzalbo Aizpuru, La lectura de la evangelización en la Nueva españa, en Historia de la lectura en México... op. cit. pp. 9-48; Elsa M. Ramírez Leyva, El libro y la lectura en el proceso de occidentalización de México, México, UnAm-CUIB, 2001. 
sus futuras obligaciones. Por ello seleccionaron como alumnos preferentemente a estos jóvenes nobles que ya habían sido sometidos a una disciplina de aprendizaje.

Así, nuevos y variados lectores surgieron en la Nueva España, para los cuales la imprenta tuvo que producir los libros necesarios. Sin duda los lectores más singulares fueron quienes hablaban las lenguas indígenas, tanto los propios indios que empezaron a ejercer la lectura tipo occidental como los españoles y criollos que debían leer en lenguas ajenas para cumplir con sus actividades.

Desde los primeros tiempos del libro en México se pensó en los niños como lectores; así en el primer Concilio provincial mexicano se señala, en el capítulo tercero, que "[...] enseñen a los niños, principalmente la doctrina cristiana porque las buenas costumbres, tanto mejor se saben y guardan quanto mas en la niñez se aprenden”. En el segundo Concilio, 1565, en uno de los avisos se refuerza lo dicho en el primer Concilio:

Que tengan escuela de castellano, y aprendan los niños a leer y escribir[...] que los maestros que enseñen a los niños, en sus escuelas hagan leer y decir la dicha doctrina[...]

Para tal fin se trajeron de España muchas cartillas pero, como ya se ha mencionado, también se imprimieron aquí en castellano y en lenguas indígenas, y a veces también en latín; se conservan pocas porque al tener un uso constante y muy bajo costo, se destruían.

Nuevos lectores fueron los indígenas para quienes se imprimieron doctrinas y catecismos en sus lenguas vernáculas, muchas de ellas muy ilustradas con la intención de alcanzar una mejor comprensión del mensaje cristiano.

También los religiosos fueron lectores de los confesionarios, de manuales para administrar otros sacramentos y de las gramáticas y vocabularios en lenguas indígenas que tuvieron que usar para poder ejercer mejor y con propiedad su ministerio y así tener una mayor comunicación con su comunidad. Igualmente los revisores de los textos que debían aprobar su publicación tenían que ser diestros en la lectura y comprensión de las lenguas indígenas como lo mandaban los concilios; por ejemplo, la obra de Maturino Gilberti Dialogo de la doctrina cristiana, fue revisada por fray Jacobo Daciano quien conocía perfectamente el michuacano. 


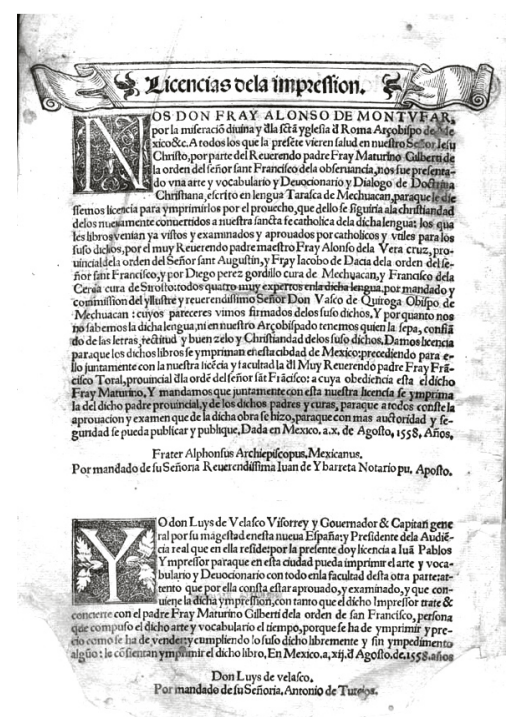

Aprobación de los Dialogos

Puede asumirse que un amplio público, criollos, españoles e indígenas, que necesitaban comunicarse entre sí y conocer sus obligaciones y derechos fueron lectores de los textos impresos en la Nueva España, muchos de ellos producto de los mandatos de los concilios. Otro ejemplo fueron los textos legislativos que tenían que respetar, o bien los libros de medicina en castellano para combatir las enfermedades, los cuales fueron muy populares y apreciados. También en otros lugares, como en Perú y Filipinas, hubo lectores de los impresos mexicanos.

\section{Conclusiones}

Ocuparse de los concilios mexicanos del siglo XVI es referirse al primer siglo de formación de este país que ahora es México y a los problemas de integración a esa otra cultura impuesta por los conquistadores.

A los concilios se los relaciona siempre con el control y la censura de los impresos, mas no se los menciona como promotores del libro y de la lectura, como también lo fueron realmente al reflexionar sobre las necesidades de conocimiento que requerían las diferentes partes de la población, ya sea para enseñar o para aprender, y asimismo fueron importantes por ordenar la impresión de diversos tipos de textos. 
Un grupo representativo de obras relacionadas con los mandatos de los concilios del siglo XVI lo constituyen las doctrinas en las lenguas indígenas; otro los vocabularios y gramáticas también en lenguas indígenas, experiencia totalmente novedosa, enriquecedora y promotora de la lectura, que sirvió de modelo para obras similares en Perú, Filipinas, Japón e India. Otro importante producto de los concilios fue la impresión de libros de música, necesarios para los actos religiosos, y los cuales requerían de gran dedicación y pericia por parte del impresor, pues como en el caso de vocabularios y gramáticas, fueron los primeros que se imprimieron fuera de Europa en el siglo XVI.

Otro grupo muy significativo de impresos, también derivado de estas resoluciones, fue el de los manuales para administrar los sacramentos, especialmente los confesionarios, que son textos de gran interés histórico y social y que fueron instrumento indispensable para implantar la nueva religión .

De este modo los concilios provinciales mexicanos del siglo XVI propiciaron ampliamente la producción del legado bibliográfico de mayor valor cultural del continente americano. 